\title{
Gender-specific risk factors for low bone mineral density in patients
}

\section{taking antipsychotics for psychosis}

Min Jhon, ${ }^{1}$ Taeyoung Yoo, ${ }^{1}$ Ju-Yeon Lee, ${ }^{1,2}$ Seon-Young Kim, ${ }^{1}$ Jae-Min Kim, ${ }^{1}$ Il-Seon Shin, ${ }^{1}$ Lana Williams, ${ }^{3}$ Michael Berk, ${ }^{3,4}$ Jin-Sang Yoon, ${ }^{1}$ Sung-Wan Kim ${ }^{1,2, *}$

1 Department of Psychiatry, Chonnam National University Medical School, Gwangju, Republic of Korea

2 Gwangju Mental Health Commission, Gwangju, Republic of Korea

3 Deakin University, IMPACT Strategic Research Centre, School of Medicine, Geelong, Australia

4 Orygen, The National Centre of Excellence in Youth Mental Health, Centre for Youth Mental Health, Florey Institute for Neuroscience and Mental Health and the Department of Psychiatry The University of Melbourne, Melbourne, Australia

* Correspondence: Sung-Wan Kim, Department of Psychiatry, Chonnam National University Medical School, 160 Baekseo-ro, Donggu, Gwangju 61469, Republic of Korea. Tel.: +82 62220 6148; Fax: +82 622252351 .

E-mail: $\underline{\text { swkim@chonnam.ac.kr }}$

This is the author manuscript accepted for publication and has undergone full peer review but has not been through the copyediting, typesetting, pagination and proofreading process, which may lead to differences between this version and the Version of Record. Please cite this article as doi: 10.1002/hup.2648

This article is protected by copyright. All rights reserved. 
Running Head: Low bone mineral density in psychosis

Key words: bone mineral density, body mass index, psychosis, serotonergic antidepressant, schizophrenia, prolactin

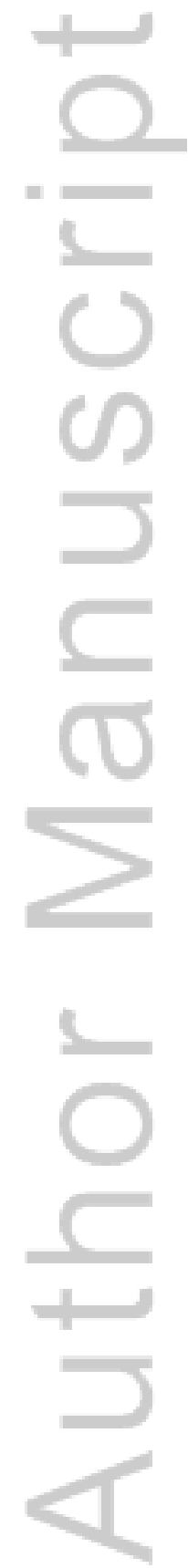

This article is protected by copyright. All rights reserved. 


\section{Abstract}

Objective: This study examined clinical and gender-specific risk factors for low bone mineral density (BMD) in adult patients with psychotic disorders.

Methods: The study included 285 community-dwelling patients with psychotic disorders. Dualenergy x-ray absorptiometry was used to measure BMD. Clinical characteristics associated with low BMD were identified with logistic regression analysis in total population and each gender.

Results: Fifty-eight (20.4\%) subjects had low BMD. Low BMD was more common in men and in patients with low body mass indices (BMIs), as well as in those with shorter treatment durations, those on Medicaid, and patients using serotonergic antidepressants. Logistic regression analysis revealed that low BMD was negatively associated with BMI and treatment duration and positively with gender (male) and serotonergic antidepressants use in the overall population. In men, low BMD was associated with treatment duration and BMI; in women, low BMD was associated with BMI, prolactin level, vitamin D, and serotonergic antidepressant use.

Conclusion: Managing the risk factors associated with low BMD among patients with psychotic disorder should be done gender-specifically. Psychotropic agents should be prescribed mindful of their effects on bone, as use of these medications is a modifiable risk factor for osteoporosis in women with psychotic disorders. 


\section{Introduction}

Psychotic disorders are common globally and often lifelong conditions characterized by varying degrees of functional disability. The life expectancy of patients with schizophrenia is reduced by 12 15 years, in part due to obesity, lack of exercise, smoking, and poor self-care (van Os \& Kapur, 2009). The physical health of those with psychotic disorders is therefore critically important.

Osteoporosis is a major yet covert, comorbidity in patients with schizophrenia that has recently attracted much clinical attention. It is characterized by low bone mineral density (BMD) and deterioration of the micro-architecture of bone tissue, with consequent increases in bone fragility and fracture susceptibility. Osteopenia, the precursor of osteoporosis, also carries an increased risk of fracture. Physical limitations, fractures, and associated complications render osteoporosis a serious public health problem associated with substantial morbidity and mortality. A recent meta-analysis of 19 studies including 2905 patients with schizophrenia revealed that the overall pooled prevalence of low bone mass (osteopenia and osteoporosis) was 51.7\%. Moreover, a subgroup analysis of 1814 Asian patients with schizophrenia reported that $58.4 \%$ had low bone mass. Compared with the general population, patients with schizophrenia had an almost twofold increased risk of low bone mass (Stubbs et al., 2014). The authors of another review investigating BMD in patients with schizophrenia who used antipsychotics argued that gender-specific risk factors of low BMD should be considered (Chen et al., 2016).

The etiology of BMD loss in patients with schizophrenia is complex and likely to be related to the disease, treatments and other lifestyle factors including smoking, reduced physical activity, alcohol abuse, vitamin D and calcium deficiencies, and polydipsia (Lean et al., 2004). Several recent studies 
have suggested that reduced BMD in schizophrenia is associated with psychotropic medications (Wu et al., 2013). Antipsychotic-induced hyperprolactinemia reduces BMD by causing hypogonadism. Also, prolactin may directly affect human osteoblasts (Seriwatanachai et al., 2009). However, some studies have found no significant correlation between prolactin level and reduced BMD (Howes et al., 2005). Several reviews and a meta-analysis reported that the evidence suggesting antipsychoticinduced hyperprolactinemia is a major risk factor for bone loss is both limited and contradictory (Kishimoto et al., 2012). In addition, several longitudinal, cross-sectional, and prospective cohort studies have explored the potential risk of reduced BMD in patients taking antidepressants (ADs), particularly selective serotonin reuptake inhibitors (SSRIs) (Haney et al., 2007; Richards et al., 2007). But most of these studies involved elderly non-psychotic patients.

Given the evidence to date, the aim of this study is to explore potentially modifiable risk factors for low BMD in community-dwelling adults with psychotic disorders. Furthermore, we sought to identify gender-specific risk factors. 


\section{Methods}

\subsection{Participants}

This is a sub study of the Gwangju Comprehensive Health Inspection for Mental Illness study, which aims to evaluate the physical health of patients with mental illness treated in community mental health centers in Gwangju, Korea. The parental study enrolled 386 patients with mental illness. Inclusion criteria of the present study were patients aged $\leq 60$ years to exclude potential agerelated idiopathic osteoporosis and patients diagnosed with psychotic disorder. Of the 386 patients enrolled, 285 subjects were finally included in the present study, of which $241(84.6 \%)$ had schizophrenia and $44(15.4 \%)$ had affective psychoses. The study was approved by Chonnam National University Hospital's Institutional Review Board. All subjects provided written informed consent before participating.

\subsection{Measures}

Basic demographic and clinical information were obtained from medical records and their case managers; psychiatric diagnoses, duration of treatment, prescribed medications and dosages, and type of medical insurance (Medicaid for disadvantaged people and Medicare for the remainder). The Clinical Global Impression (CGI) Scale was administered by case managers to evaluate global symptom severity and functional impairment, and assessed suicidal ideation. This measure is used in general health screening by the Korean National Health Insurance Service to evaluate physical activity and depressive symptoms (Corporation). Specifically, physical activity was measured by three items of the International Physical Activity Questionnaire (IPAQ)-Short Form (vigorous 
physical activities, moderate physical activities, walk) (Sjøstrom et al., 2000). Participants were categorized into two groups according to the IPAQ scoring protocol (IPAQ, 2005). The active group was defined as a) $\geq 3$ days of vigorous activity or b) $\geq 5$ days of moderate physical activities or walking at least 30 minutes per day or c) $\geq 5$ days of any combination of walking, moderate or vigorous activities. Those participants who did not meet the criteria for active group membership were categorized as inactive. Depressive symptoms were measured by four items of the Center for Epidemiological Studies Depression Scale (bothered by things, poor appetite, felt blue, felt depressed) (Radloff, 1977). Dietary habits were measured using 20 questions based on dietary guidance published by the Korean Ministry for Health, Welfare and Family Affairs. The dietary questionnaire consists of three subcategories including 5 items for diet regularity, 6 items for balanced diet, and 9 items for unhealthy diet and habits. In this study, the dairy intake item was used as a proxy variable for calcium intake. Dairy intake $\geq 3$ days per week was defined as regular intake and dairy intake $\leq 2$ days per week was defined as irregular intake. Score on the balanced diet subscale was also used as a variable for habitual diet.

Lumbar spine (L1-L4) BMD was determined by dual-energy X-ray absorptiometry (Prodigy; GE, Madison, WI, USA). The World Health Organization defines osteopenia as a BMD of more than 1 but less than 2.5 standard deviations below the mean for young adults ( $\mathrm{T}$ scores $<-1$ and $>-2.5$ ) and osteoporosis as a BMD 2.5 standard deviations or more below the young adult mean (T score $\leq-2.5)$. Normal $\mathrm{BMD}$ is defined as a $\mathrm{BMD} \geq 1$ standard deviations above the mean ( $\mathrm{T}$ score $\geq-1$ ). Low bone mass was defined as a BMD T score of $<-1$.

Weight and height were measured to the nearest $0.1 \mathrm{~kg}$ and $0.1 \mathrm{~cm}$, respectively, and body mass index (BMI) calculated as weight $/$ height $^{2}\left(\mathrm{~kg} / \mathrm{m}^{2}\right)$. Fasting venous blood samples were obtained to 
assess prolactin and vitamin D levels. The participants were categorized into two groups according to the median value of vitamin $\mathrm{D}(14.3 \mathrm{ng} / \mathrm{mL}$ in total, $15.3 \mathrm{ng} / \mathrm{mL}$ in men and $14.0 \mathrm{ng} / \mathrm{mL}$ in women). It is notable that the standard for sufficient vitamin D levels might be different according to ethnicity (Mithal et al., 2009).

Patients were divided into those on relatively prolactin-sparing and non-prolactin-sparing antipsychotics. Half of all subjects were on antipsychotic combination therapy. Thus, those on prolactin-sparing antipsychotics only were included in the prolactin-sparing group; these included aripiprazole, quetiapine, clozapine and olanzapine. Risperidone-equivalent doses were calculated to assess dose-dependent drug effects. Among antidepressants, serotonergic antidepressants included selective serotonin reuptake inhibitors (SSRIs), mirtazapine, and trazodone $(n=42)$. Bupropion, tianeptine, and tricyclic antidepressants were not included in the category of serotonergic antidepressants $(\mathrm{n}=18)$.

\subsection{Statistical Analysis}

The participants were divided into two groups based on BMD status according to gender. Sociodemographic and clinical characteristics were compared between the two groups using the independent $t$-test, chi-squared test, and Mann-Whitney $U$-test, as appropriate. Factors associated with low BMD in univariate analyses $(p<0.1)$ were tested in the models. Age, prolactin level, and vitamin D group were simultaneously entered into the multivariate analysis due to previously been shown to affect BMD. As formal depression scale data were not available, current suicidal ideation was included to as an index of depressive symptoms when analyzing serotonergic antidepressants use. Factors for which equal variance was not assumed were log transformed for the regression analysis. 
All data were analyzed using SPSS for Windows ver. 23.0. Statistical significance was defined as $p<$ 0.05 (two-tailed).

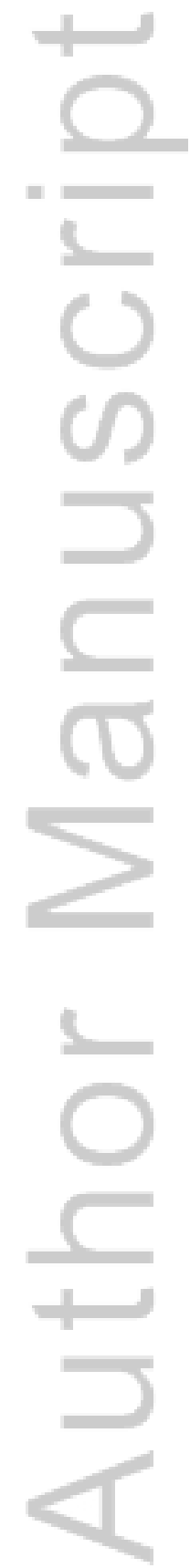

This article is protected by copyright. All rights reserved. 


\section{Results}

Two hundred and eighty five patients were included [160 (56.1\%) males, 118 females; mean age $40 \pm 11$ years]. The median duration of antipsychotic treatment was 13 years (interquartile range 6-22 years). Mean BMI was $26.0 \pm 4.8 \mathrm{~kg} / \mathrm{m}^{2}$, and $70.9 \%$ of the patients were considered overweight $\left(\mathrm{BMI}>23 \mathrm{~kg} / \mathrm{m}^{2}\right)$. BMI tended to be associated positively with the duration of treatment, although this association was not significant $(r=0.148, p=0.070)$.

Of the participants, $58(20.4 \%)$ had low BMD ( $n=52$ osteopenia and $n=6$ osteoporosis). Table 1 lists the sociodemographic and clinical characteristics of the groups according to BMD and sex. Low BMD was associated with lower BMI, shorter treatment duration, male gender, Medicaid service, and use of serotonergic antidepressants (all $p<0.05$ ); otherwise the groups were similar in regards to age, prolactin and vitamin D levels, exercise, depressive symptoms, antipsychotic dose, CGI score, dairy intake, balanced diet, suicidal ideation, prolactin sparing antipsychotic use and smoking status. Prolactin level, antipsychotic dose, and smoking status differed between males and females (all $p<0.05$ ); otherwise the groups were similar in regards to other demographic and clinical characteristics. Table 2 summarizes the sociodemographic and clinical characteristics according to low BMD for males and females. Among men, lower BMI and shorter treatment duration were associated significantly with reduced BMD $(p<0.05)$. For women, lower BMI, vitamin D, and serotonergic antidepressant use was associated with reduced $\operatorname{BMD}(p<0.05)$. Table 3 presents the multivariate analysis according to the whole group and by sex. After adjustment for other confounding variables, low BMD was associated positively with serotonergic antidepressant use [adjusted odds ratio $(\mathrm{OR})=2.5,95 \%$ confidence interval $(\mathrm{CI})=1.1-5.8$ ] and male gender $($ adjusted 
$\mathrm{OR}=3.0,95 \% \mathrm{CI}=1.3-6.5)$, and negatively with $\mathrm{BMI}$ (adjusted $\mathrm{OR}=0.8,95 \% \mathrm{CI}=0.7-0.9$ ) and treatment duration (adjusted $\mathrm{OR}=0.7,95 \% \mathrm{CI}=0.5-0.9$ ).

Subgroup analysis revealed that low BMD in men was significantly associated with BMI $(\mathrm{OR}=$ $0.8,95 \% \mathrm{CI}=0.7-0.9)$ and treatment duration $(\mathrm{OR}=0.6,95 \% \mathrm{CI}=0.4-0.9)$. In women, low $\mathrm{BMD}$ was significantly associated with $\mathrm{BMI}(\mathrm{OR}=0.8,95 \% \mathrm{CI}=0.7-0.9)$, prolactin level $(\mathrm{OR}=2.5,95 \%$ $\mathrm{CI}=1.1-5.3)$, low vitamin $\mathrm{D}$ group $(\mathrm{OR}=12.5,95 \% \mathrm{CI}=1.9-84.6)$ and serotonergic antidepressant use $(\mathrm{OR}=34,95 \% \mathrm{CI}=3.8-306.6)$. 


\section{Discussion}

In this study, several gender-specific risk factors were found to be associated with low BMD. The proportion of subjects with low BMD was significantly greater in men than in women. In men, shorter treatment duration and low BMI were associated with low BMD. In women, antipsychoticinduced hyperprolactinemia, low BMI, low vitamin D and serotonergic antidepressant use were associated significantly with lower BMD. To our knowledge, this study is the first to identify serotonergic antidepressant use as an independent risk factor for reduced BMD in adult women with psychotic disorders.

Many studies have now shown serotonergic antidepressant use to be associated with low BMD in both population based and clinical samples of patients with depression. One population-based cohort study of 5008 adults showed that daily SSRI use lowered hip BMD and doubled the risk of fragility fracture; the effects were dose dependent (Richards et al., 2007). In a study similar to ours, 83 boys on risperidone and SSRIs exhibited a reduced radial trabecular BMD (Calarge et al., 2010). Our study subjects also explored non-elderly adults but the association between serotonergic antidepressant use and low BMD was significant even after adjusting for confounding factors. Because our study participants had psychotic disorders, it appears that the underlying susceptibility of such disorders, associated risk factors, and medication effects may interact with serotonergic antidepressant use to reduce BMD.

Serotonin plays a significant role in bone remodeling and SSRIs may affect bone metabolism by regulating the levels of circulating serotonin and inhibiting the serotonin transporter. Yadav et al. were the first to report that circulating serotonin bound directly to the osteoblast 5-HT1B receptor and reduced cell proliferation (Yadav et al., 2008). A recent study showed that serotonin controlled 
osteoclastogenesis via a paracrine/autocrine mechanism and that osteoclasts were the source of locally synthesized serotonin in bone microenvironments (Chabbi-Achengli et al., 2012). SSRIs specifically reduced both osteoclast and osteoblast numbers via a mechanism other than modulation of the extracellular 5-HT concentrations (Hodge et al., 2013). Another study found that serotonin transporter gene 5-HTTVNTR polymorphisms were more common in osteoporotic patients (Ferreira et al., 2011). Although the exact mechanism by which serotonergic pathways affect bone is unclear, it appears that SSRIs may exert anti-anabolic skeletal effects by pharmacologically inhibiting the serotonin transporter (Fernandes et al., 2016).

Our study revealed male patients were 3 -fold more likely than females to have a low BMD, contrary to the notion that females are at greater risk of low BMD (Klibanski et al., 2001). Several studies of psychiatric patients also reported significantly lower BMDs in men on neuroleptics than in women (Hummer et al., 2005). The higher prevalence of smoking and alcohol use among males may negatively affect BMD. Women have also been suggested to pay more attention than men to nutrition and exercise, and therefore to experience less osteoporosis. In our study, however, we found that smoking status was not significantly associated with low BMD in men. In addition, the levels of vitamin $\mathrm{D}$ and exercise did not differ significantly by gender. Further studies are needed to investigate why low BMD is more prevalent in men with psychosis than in female patients.

BMI was significantly lower in subjects with low BMD compared with normal BMD in both genders. Although several recent studies have suggested that obesity is a risk factor for certain fractures, extensive epidemiological studies have shown that elevated body weight or BMI is positively associated with increased BMD. This positive association is explained by the greater mechanical loads placed on bone by larger body masses, with a consequent increase in BMD 
(Caffarelli et al., 2014). Estrogen production from abundant adipose tissue and increased leptin resistance also exert protective effects on BMD (Reid, 2010). The mean BMI $\left(26.0 \mathrm{~kg} / \mathrm{m}^{2}\right)$ of our subjects was higher than normal, possibly attributable to the use of antipsychotics. As we also found, a BMI of 26-28 kg/m² afforded some protection against low BMD, whereas a lower BMI of 22-24 $\mathrm{kg} / \mathrm{m}^{2}$ increased the risk (Wardlaw, 1996).

No consensus has been established on the association between decreased BMD and antipsychotic treatment duration. We found that shorter treatment duration was significantly associated with low BMD and that hyperprolactinemia was not associated with low BMD in men. One possible cause is the protective effect of body weight on BMD. Overweight status was very prevalent among patients in this study compared with the Korean general population, and treatment duration tended to be associated with high BMI. Taken together, these findings indirectly suggest that weight gain during treatment has a protective effect on low BMD in men with schizophrenia. This begs the question, why do women differ? One possible answer is that the duration of hyperprolactinemia induced by antipsychotics affected BMD more critically (Kishimoto et al., 2008) than did the duration of weight gain in women, as hyperprolactinemia was associated independently with low BMD only in women.

Our finding of significantly higher prolactin levels in women than in men is in line with the findings of previous studies (Kinon et al., 2013). Gender differences in the effects of hyperprolactinemia might be attributable to the degree of hyperprolactinemia and interaction with estrogen. A recent review showed that the results of 13 of 24 studies in which schizophrenia was treated with antipsychotic medications supported an association between high prolactin level and low BMD, whereas findings of the remaining studies did not (De Hert et al., 2016). These inconclusive 
results might be attributed to differential sex effects of hyperprolactinemia on low BMD. Although hyperprolactinemia was associated with low BMD, use of prolactin-sparing antipsychotics did not protect against low BMD in our study. One possible factor is that antipsychotics, including D2 receptor antagonists, might also affect bone mass via suppressing human osteoclastogenesis (Hanami et al., 2013). Further studies are needed to investigate the relationship between bone mass and antipsychotics considering the effect of prolactin and dopamine signaling on bone.

Several studies have found that a low serum 25-OHD level is associated with low BMD (SadatAli et al, 2011). We also found that low vitamin D was significantly associated with low BMD in women. In this study, the median value of vitamin D level of participants was $14.3 \mathrm{ng} / \mathrm{mL}$, which is below the level for vitamin D insufficiency $(20 \mathrm{ng} / \mathrm{mL})$ proposed in Western countries. However, it is unclear whether vitamin D supplementation prevents osteoporosis and falls (Sanders et al., 2010). Further research is needed to examine the benefits of vitamin D supplementation on bone, particularly in female patients taking serotonergic antidepressants and antipsychotics inducing hyperprolactinemia.

Age showed no significant associations with low BMD in our study, although the age range in our sample was narrow. Osteoporosis is an age-related disorder and elderly subjects are included in most studies of the condition. However, the mean age of our study participants was less than 40 years and $81 \%$ were younger than 50 . One study of premenopausal bone loss in 225 Caucasian females found that spinal bone mass peaked in the mid-30s (Rodin et al., 1990). Another study of 265 premenopausal Caucasian females aged 8-50 years found that lumbar spine BMD peaked at the age of 18 years and did not change thereafter to the age of 50 years (Matkovic et al., 1994). Thus, age may not be a significant risk factor for low BMD in non-elderly adults. 
Among the risk factors that we identified, serotonergic antidepressant use could be easily regulated, and there appear to be large between agent differences in terms of effects on bone (Hodge et al., 2013). Concomitant antidepressants were prescribed to about $20 \%$ of subjects diagnosed with psychotic disorders in this study. A recent review found that $40 \%$ of schizophrenia patients in Western countries and $8.7 \%$ in Asian countries were on adjunctive ADs (Mao et al., 2015). However, the 2009 Psychopharmacological Treatment Recommendations and Summary Statements of the Schizophrenia Patient Outcomes Research Team (PORT) altered the earlier recommendation that antidepressants should be used to treat depressive symptoms in schizophrenia patients because evidence of its utility was lacking (Buchanan et al., 2010). Also, a recent review of 18 doubleblinded, placebo-controlled clinical trials of adjunctive antidepressants found no significant effects were apparent in 11 of these (Mao et al., 2015). Considering that serotonergic antidepressants reduce BMD and do not effectively treat the depressive symptoms of schizophrenia, they should be carefully prescribed. Alternatives to serotonergic antidepressants should thus be considered.

This study has several limitations. First, we did not measure sex hormone levels. Thus, the association between prolactin level and low BMD should be interpreted carefully. Second, known confounding factors including other medications known to affect bone, sunlight exposure and negative symptoms were not controlled. Third, no formal measure of depression was used to control for the severity of depression, which has been shown to be associated with bone independent of SSRI use (Williams et al., 2016). However, the association between serotonergic antidepressant use and low BMD was maintained after adjusting for the presence of suicidal ideation, which may be associated with depression. Finally, dose-response relationship by duration of antidepressants use was not investigated in this study. 
Nevertheless, this study has important clinical and research implications, including the demonstration of the gender effects of hyperprolactinemia on low BMD, which might explain the inconclusive results obtained in other studies. Whereas high BMI is associated with metabolic syndrome in patients taking antipsychotics, low BMI is associated with low BMD.

In conclusion, our study revealed several risk factors associated with low BMD among patients with psychotic disorder and it showed gender difference. These factors should be managed to predict and prevent serious consequences of osteoporosis. Furthermore, psychotropic agents which affects bone should be prescribed mindful and alternatives should be considered.

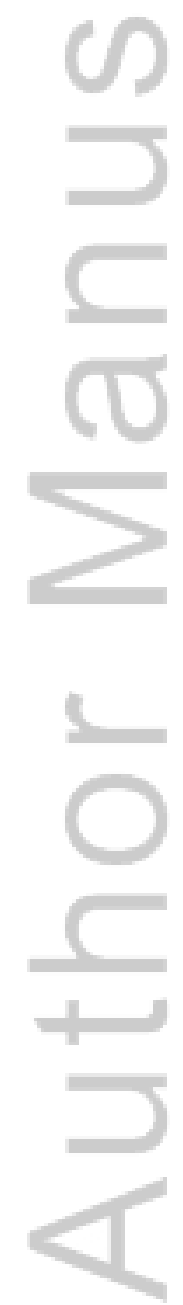




\section{SOURCE OF FUNDING}

This study was supported by a grant of the Basic Science Research Program through the National Research Foundation of Korea (NRF) funded by the Ministry of Education (NRF2014R1A1A4A01005245).

\section{ACKNOWLEDGEMENTS}

This research work was conducted as part of the Gwangju Mental Health Demonstration Project supported by Ministry of Health \& Welfare and Gwangju Metropolitan city, Republic of Korea. We wish to thank mental health workers of community mental health centers in Gwangju for their assistance of this study. MB is supported by a NHMRC Senior Principal Research Fellowship 1059660. LJW is supported by a NHMRC Career Development Fellowship (1064272)

\section{CONFLICT OF INTERESTS}

J.M.K. has received grants from Ministry of Health and Welfare, Republic of Korea, Lundbeck, Eli Lilly, and Otsuka. L.W. has received Grant/Research support from Eli Lilly, Pfizer, The University of Melbourne, Deakin University and the NHMRC. M.B. has received Grant/Research Support from the NIH, Cooperative Research Centre, Simons Autism Foundation, Cancer Council of Victoria, Stanley Medical Research Foundation, MBF, NHMRC, Beyond Blue, Rotary Health, Geelong Medical Research Foundation, Bristol Myers Squibb, Eli Lilly, Glaxo SmithKline, Meat and Livestock Board, Organon, Novartis, Mayne Pharma, Servier, and Woolworths. J.S.Y. has received research funds from Sanofi-Aventis, Janssen, Roche, Otsuka, Lundbeck, and Sumitomo Pharmaceutical. S.W.K. has received grants from Ministry of Education and Ministry of Health and 
Welfare, Republic of Korea, Handok, Janssen, Mitsubishi Tanabe, and Otsuka. Other authors have declared no conflict of interests in relation to the subject of this study.

\section{REFERENCES}

Buchanan, R. W., Kreyenbuhl, J., Kelly, D. L., Noel, J. M., Boggs, D. L., Fischer, B. A., ... Keller, W. (2010). The 2009 schizophrenia PORT psychopharmacological treatment recommendations and summary statements. Schizophr Bull, 36(1), 71-93.

Caffarelli, C., Alessi, C., Nuti, R., \& Gonnelli, S. (2014). Divergent effects of obesity on fragility fractures. Clin Interv Aging, 9, 1629-1636.

Calarge, C. A., Zimmerman, B., Xie, D., Kuperman, S., \& Schlechte, J. A. (2010). A cross-sectional evaluation of the effect of risperidone and selective serotonin reuptake inhibitors on bone mineral density in boys. J Clin Psychiatry, 71(3), 338-347.

Chabbi-Achengli, Y., Coudert, A. E., Callebert, J., Geoffroy, V., Cote, F., Collet, C., \& de Vernejoul, M. C. (2012). Decreased osteoclastogenesis in serotonin-deficient mice. Proc Natl Acad Sci US A, 109(7), 2567-2572.

Chen, C. Y., Lane, H. Y., \& Lin, C. H. (2016). Effects of Antipsychotics on Bone Mineral Density in Patients with Schizophrenia: Gender Differences. Clin Psychopharmacol Neurosci, 14(3), 238-249.

International Physical Activity Questionnaire. Guidelines for Data Processing and Analysis of the International Physical Activity Questionnaire (IPAQ) - Short and Long Forms, 2005. http://www.ipaq.ki.se/scoring.pdf [accessed 15 February 2014].

De Hert, M., Detraux, J., \& Stubbs, B. (2016). Relationship between antipsychotic medication, serum 
prolactin levels and osteoporosis/osteoporotic fractures in patients with schizophrenia: a critical literature review. Expert Opin Drug Saf, 15(6), 809-823.

Fernandes, B. S., Hodge, J. M., Pasco, J. A., Berk, M., \& Williams, L. J. (2016). Effects of Depression and Serotonergic Antidepressants on Bone: Mechanisms and Implications for the Treatment of Depression. Drugs Aging, 33(1), 21-25.

Ferreira, J. T., Levy, P. Q., Marinho, C. R., Bicho, M. P., \& Mascarenhas, M. R. (2011). Association of serotonin transporter gene polymorphism 5HTTVNTR with osteoporosis. Acta Reumatol Port, 36(1), 14-19.

Hanami, K., Nakano, K., Saito, K., Okada, Y., Yamaoka, K., Kubo, S., . . . Tanaka, Y. (2013). Dopamine D2-like receptor signaling suppresses human osteoclastogenesis. Bone, 56(1), 1-8.

Haney, E. M., Chan, B. K., Diem, S. J., Ensrud, K. E., Cauley, J. A., Barrett-Connor, E., . . Bliziotes, M. M. (2007). Association of low bone mineral density with selective serotonin reuptake inhibitor use by older men. Arch Intern Med, 167(12), 1246-1251.

Hodge, J. M., Wang, Y., Berk, M., Collier, F. M., Fernandes, T. J., Constable, M. J., . . Williams, L. J. (2013). Selective serotonin reuptake inhibitors inhibit human osteoclast and osteoblast formation and function. Biol Psychiatry, 74(1), 32-39.

Howes, O. D., Wheeler, M. J., Meaney, A. M., O'Keane, V., Fogelman, I., Blake, G., . . Smith, S. (2005). Bone mineral density and its relationship to prolactin levels in patients taking antipsychotic treatment. J Clin Psychopharmacol, 25(3), 259-261.

Hummer, M., Malik, P., Gasser, R. W., Hofer, A., Kemmler, G., Moncayo Naveda, R. C., . . . Fleischhacker, W. W. (2005). Osteoporosis in patients with schizophrenia. Am J Psychiatry, $162(1), 162-167$. 
Kinon, B. J., Liu-Seifert, H., Stauffer, V. L., \& Jacob, J. (2013). Bone loss associated with hyperprolactinemia in patients with schizophrenia. Clin Schizophr Relat Psychoses, 7(3), 115-123.

Kishimoto, T., De Hert, M., Carlson, H. E., Manu, P., \& Correll, C. U. (2012). Osteoporosis and fracture risk in people with schizophrenia. Curr Opin Psychiatry, 25(5), 415-429.

Kishimoto, T., Watanabe, K., Shimada, N., Makita, K., Yagi, G., \& Kashima, H. (2008). Antipsychotic-induced hyperprolactinemia inhibits the hypothalamo-pituitary-gonadal axis and reduces bone mineral density in male patients with schizophrenia. J Clin Psychiatry, 69(3), 385-391.

Klibanski, A., Adams-Campbell, L., Bassford, T. L., Blair, S. N., Boden, S. D., Dickersin, K., . . . Hruska, K. (2001). Osteoporosis prevention, diagnosis, and therapy. JAMA, 285(6), 785-795.

Lean, M., \& De Smedt, G. (2004). Schizophrenia and osteoporosis. Int Clin Psychopharmacol, 19(1), 31-35.

Mao, Y. M., \& Zhang, M. D. (2015). Augmentation with antidepressants in schizophrenia treatment: benefit or risk. Neuropsychiatr Dis Treat, 11, 701-713.

Matkovic, V., Jelic, T., Wardlaw, G. M., Ilich, J. Z., Goel, P. K., Wright, J. K., . . Heaney, R. P. (1994). Timing of peak bone mass in Caucasian females and its implication for the prevention of osteoporosis. Inference from a cross-sectional model. J Clin Invest, 93(2), 799-808.

Mithal, A., Wahl, D., Bonjour, J.-P., Burckhardt, P., Dawson-Hughes, B., Eisman, J., . . MoralesTorres, J. (2009). Global vitamin D status and determinants of hypovitaminosis D. Osteoporos int, 20(11), 1807-1820.

Radloff, L. S. (1977). The CES-D scale: A self-report depression scale for research in the general 
population. Applied psychological measurement, 1(3), 385-401.

Reid, I. R. (2010). Fat and bone. Arch Biochem Biophys, 503(1), 20-27.

Richards, J. B., Papaioannou, A., Adachi, J. D., Joseph, L., Whitson, H. E., Prior, J. C., \& Goltzman, D. (2007). Effect of selective serotonin reuptake inhibitors on the risk of fracture. Arch Intern Med, 167(2), 188-194.

Rodin, A., Murby, B., Smith, M. A., Caleffi, M., Fentiman, I., Chapman, M. G., \& Fogelman, I. (1990). Premenopausal bone loss in the lumbar spine and neck of femur: a study of 225 Caucasian women. Bone, 11(1), 1-5.

Sanders, K. M., Stuart, A. L., Williamson, E. J., Simpson, J. A., Kotowicz, M. A., Young, D., \& Nicholson, G. C. (2010). Annual high-dose oral vitamin D and falls and fractures in older women: a randomized controlled trial. JAMA, 303(18), 1815-1822.

Seriwatanachai, D., Krishnamra, N., \& van Leeuwen, J. P. (2009). Evidence for direct effects of prolactin on human osteoblasts: Inhibition of cell growth and mineralization. J Cell Biochem, 107(4), 677-685.

Sjøstrom, M., Ekelund, U., Poortvliet, E., Hurting-Wennlof, A., \& Yngve, A. (2000). Assessment of physical activity using IPAQ (version 4) and activity monitors (CSA). Meas. Phys. Educ. Exerc. Sci, 4, 263-264.

Stubbs, B., De Hert, M., Sepehry, A. A., Correll, C. U., Mitchell, A. J., Soundy, A., . . Vancampfort, D. (2014). A meta-analysis of prevalence estimates and moderators of low bone mass in people with schizophrenia. Acta Psychiatr Scand, 130(6), 470-486.

van Os, J., \& Kapur, S. (2009). Schizophrenia. Lancet, 374(9690), 635-645.

Wardlaw, G. M. (1996). Putting body weight and osteoporosis into perspective. Am J Clin Nutr, 63(3 
Suppl), 433s-436s.

Williams, L. J., Pasco, J. A., Jackson, H., Kiropoulos, L., Stuart, A. L., Jacka, F. N., \& Berk, M. (2016). Depression as a risk factor for fracture in women: A 10 year longitudinal study. $J$ Affect Disord, 192, 34-40.

Wu, H., Deng, L., Zhao, L., Zhao, J., Li, L., \& Chen, J. (2013). Osteoporosis associated with antipsychotic treatment in schizophrenia. Int J Endocrinol, 2013, 167138.

Yadav, V. K., Ryu, J. H., Suda, N., Tanaka, K. F., Gingrich, J. A., Schutz, G., . . Karsenty, G. (2008). Lrp5 controls bone formation by inhibiting serotonin synthesis in the duodenum. Cell, 135(5), 825-837. 
Table 1. Comparisons of clinical characteristics of patients with or without low bone mineral density

\begin{tabular}{|c|c|c|c|c|c|c|c|}
\hline & \multirow{2}{*}{$\begin{array}{c}\text { Total } \\
(\mathrm{n}=285)\end{array}$} & \multicolumn{2}{|c|}{ Low BMD } & \multirow{2}{*}{$p$-value } & \multicolumn{2}{|c|}{ Gender } & \multirow[b]{2}{*}{$p$-value } \\
\hline$=$ & & $\begin{array}{c}\text { No }(\mathrm{n}=227) \\
79.6 \%\end{array}$ & $\begin{array}{c}\text { Yes }(\mathrm{n}=58), \\
20.4 \%\end{array}$ & & Male $(n=160)$ & Female $(n=125)$ & \\
\hline Age, mean (SD), y & $40.0(11.1)$ & $39.8(10.9)$ & $40.8(12.2)$ & 0.527 & $40.2(11.0)$ & $39.8(11.4)$ & 0.751 \\
\hline BMI, mean (SD), kg/m² & $26.0(4.8)$ & $26.6(4.7)$ & $23.3(4.3)$ & $<0.001$ & $25.7(4.6)$ & $26.2(5.0)$ & 0.401 \\
\hline Prolactin, Med. (IQR), ng/mL & $24.4(10-56.3)$ & $23(10.0-56)$ & $26.2(10.6-58)$ & 0.468 & $20(8.0-38.8)$ & $33.4(15-101)$ & $<0.001$ \\
\hline DOI, Med. (IOR), years & $13(6-22)$ & $14(6-24)$ & $12(4-20)$ & 0.031 & $14(6-22)$ & $12(6-24)$ & 0.653 \\
\hline $\begin{array}{l}\text { Depressive symptoms, Med. (IQR), } \\
\text { score }\end{array}$ & $5.5(4-8)$ & $6(4-8)$ & $5(4-8)$ & 0.810 & $5(4-8)$ & $6(4-7)$ & 0.859 \\
\hline Dosage of AP. ${ }^{\mathrm{a}}$, Med. (IQR), mg & $3.5(2-6)$ & $4(2-7)$ & $3(2-4)$ & 0.111 & $3(2-6)$ & $4(2.2-6.5)$ & 0.032 \\
\hline CGI, Med. (IQR), score & $4(3-4)$ & $4(3-4)$ & $4(3-4)$ & 0.716 & $4(3-4)$ & $4(3-5)$ & 0.261 \\
\hline Balanced diet, Med. (IQR), score & $10(8-12)$ & $10(8-12)$ & $9(8-10)$ & 0.298 & $9(8-11)$ & $10(8-12)$ & 0.266 \\
\hline Regular ( $\geq 3 /$ week) & $133(46.7)$ & $107(80.5)$ & $26(19.5)$ & & $70(52.6)$ & $63(47.4)$ & \\
\hline Irregular ( $\leq 2 /$ week $)$ & $149(52.3)$ & $118(79.2)$ & $31(20.8)$ & ניו & $89(59.7)$ & $60(40.3)$ & 0.250 \\
\hline
\end{tabular}




\begin{tabular}{|c|c|c|c|c|c|c|c|c|}
\hline \multirow[t]{2}{*}{ Physical activity } & Inactive & $153(57.1)$ & $123(80.4)$ & $30(19.6)$ & \multirow{2}{*}{0.936} & $87(56.9)$ & $66(43.1)$ & \multirow{2}{*}{0.630} \\
\hline & Active & $115(42.9)$ & $92(80)$ & $23(20)$ & & $62(53.9)$ & $53(46.1)$ & \\
\hline \multirow{2}{*}{$\begin{array}{l}\text { Medical } \\
\text { insurance }\end{array}$} & Medicare & $125(45.5)$ & $107(85.6)$ & $18(14.4)$ & \multirow{2}{*}{0.025} & $63(50.4)$ & $62(49.6)$ & \multirow{2}{*}{0.138} \\
\hline & Medicaid & $150(54.5)$ & $112(74.7)$ & $38(25.3)$ & & $89(59.3)$ & $61(40.7)$ & \\
\hline \multirow{2}{*}{ Suicide idea } & Yes & $75(26.6)$ & $61(81.3)$ & $14(18.7)$ & \multirow[b]{2}{*}{0.697} & $36(48)$ & $39(52)$ & \multirow[b]{2}{*}{0.102} \\
\hline & No & $207(73.4)$ & $164(79.2)$ & $43(20.8)$ & & $122(58.9)$ & $85(41.1)$ & \\
\hline \multirow{2}{*}{$\begin{array}{l}\text { Low Vitamin D } \\
\text { group }\end{array}$} & Yes & $143(50.2)$ & $109(76.2)$ & $24(16.9)$ & \multirow{2}{*}{0.149} & $80(56.3)$ & $62(43.7)$ & \multirow{2}{*}{0.947} \\
\hline & No & $142(49.8)$ & $118(83.1)$ & $34(23.8)$ & & $80(55.9)$ & $63(44.1)$ & \\
\hline \multirow{2}{*}{$\begin{array}{l}\text { PRL-sparing } \\
\text { antipsychotics }\end{array}$} & Yes & $71(27.8)$ & $58(81.7)$ & $13(18.3)$ & \multirow[b]{2}{*}{0.608} & $41(57.7)$ & $30(42.3)$ & \multirow[b]{2}{*}{0.625} \\
\hline & No & $184(72.2)$ & $145(78.8)$ & $39(21.2)$ & & $100(54.3)$ & $84(45.7)$ & \\
\hline \multirow[t]{2}{*}{ Smoking } & Yes & $65(24.9)$ & $54(83.1)$ & $11(16.9)$ & \multirow{2}{*}{0.539} & $56(86.2)$ & $9(13.8)$ & \multirow{2}{*}{$<0.001$} \\
\hline & No & $196(75.1)$ & $156(79.6)$ & $40(20.4)$ & & $91(46.4)$ & $105(53.6)$ & \\
\hline \multirow{2}{*}{$\begin{array}{l}\text { Serotonergic } \\
\text { antidepressant }\end{array}$} & Yes & $42(15.6)$ & $28(66.7)$ & $14(33.3)$ & \multirow{2}{*}{0.015} & $26(61.9)$ & $16(38.1)$ & \multirow{2}{*}{0.402} \\
\hline & No & $228(84.4)$ & $189(82.9)$ & $39(17.1)$ & & $124(54.4)$ & $104(45.6)$ & \\
\hline
\end{tabular}


* $\chi 2$ test, $\mathrm{t}$ test, or Mann-Whitney U test as appropriate; CGI=Clinical Global Impression; AP, antipsychotics; DOI, duration of illness; $\mathrm{PRL}=$ prolactin; Med.=median; $\mathrm{SD}=$ standard deviation; $\mathrm{IQR}=$ interquartile range.

${ }^{a}$ Risperidone-equivalent doses were calculated.

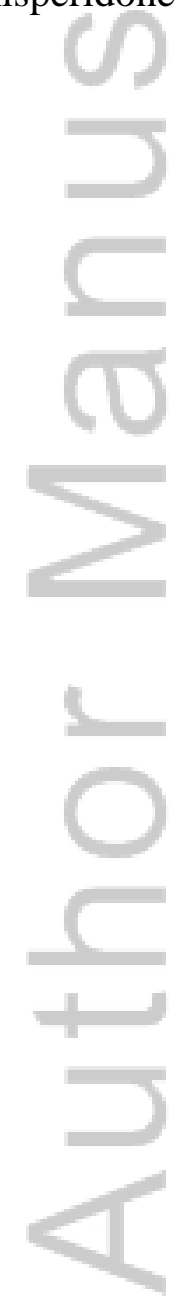


Table 2. Comparisons of clinical characteristics of gender difference with or without low BMD

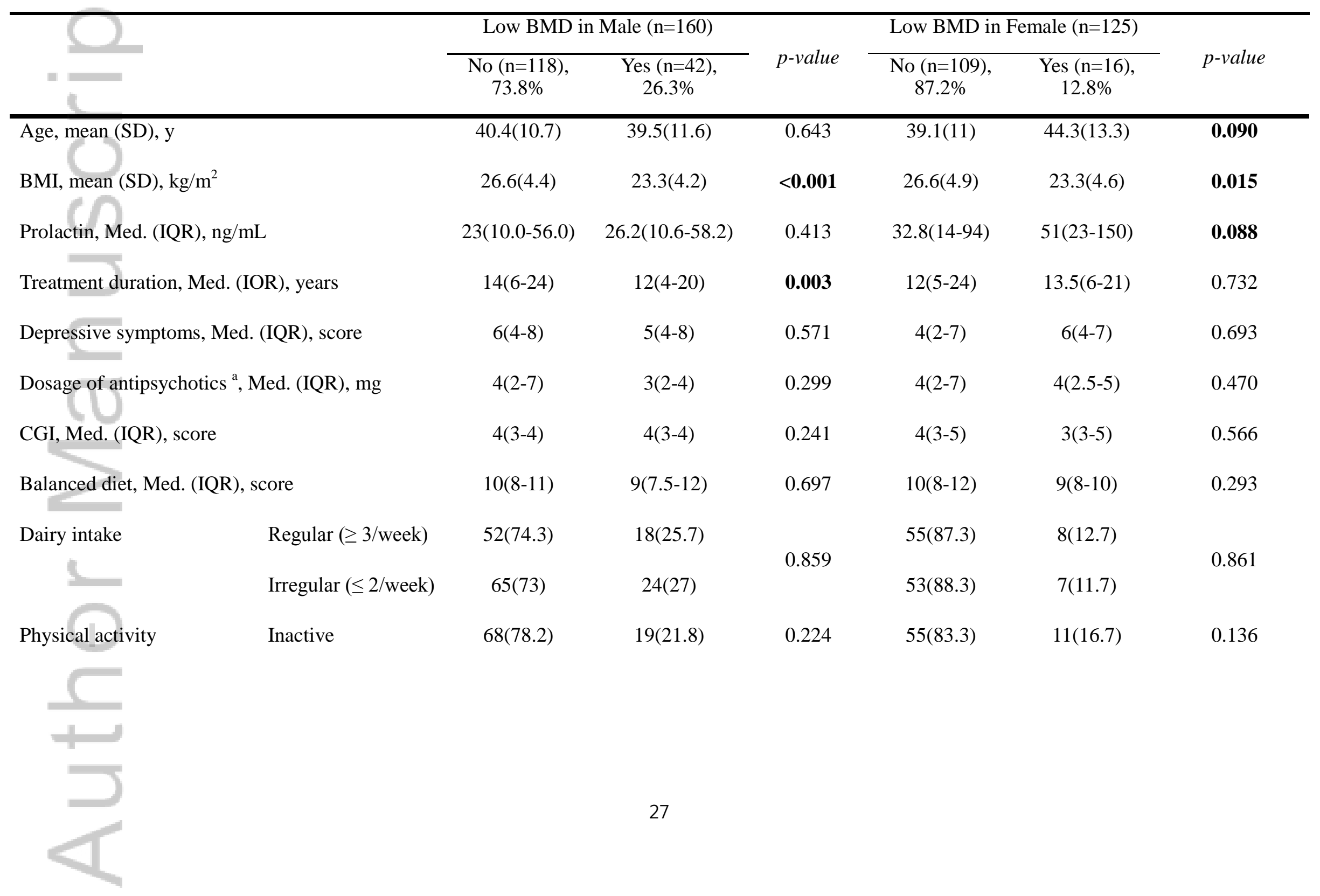

This article is protected by copyright. All rights reserved. 


\begin{tabular}{|c|c|c|c|c|c|c|c|}
\hline 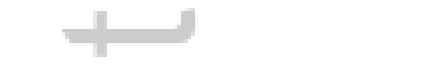 & Active & $43(69.4)$ & $19(30.6)$ & & $49(92.5)$ & $4(7.5)$ & \\
\hline Medical insurance & Medicare & $50(79.4)$ & $13(20.6)$ & \multirow[b]{2}{*}{0.181} & $57(91.9)$ & $5(8.1)$ & \multirow[b]{2}{*}{0.100} \\
\hline$=$ & Medicaid & $62(69.7)$ & $27(30.3)$ & & $50(82)$ & $11(18)$ & \\
\hline \multirow[t]{2}{*}{ Suicide idea } & Yes & $27(75)$ & $9(25)$ & \multirow[b]{2}{*}{0.807} & $34(87.2)$ & $5(12.8)$ & \multirow{2}{*}{0.867} \\
\hline & No & $89(73)$ & $33(27)$ & & $75(88.2)$ & $10(11.8)$ & \\
\hline \multirow[t]{2}{*}{ Low Vitamin D group } & Yes & $57(71.3)$ & $23(28.7)$ & \multirow[b]{2}{*}{0.472} & $51(81)$ & $12(19)$ & \multirow[b]{2}{*}{0.035} \\
\hline & No & $61(76.3)$ & $19(23.8)$ & & $58(93.5)$ & $4(6.5)$ & \\
\hline \multirow[t]{2}{*}{ PRL-sparing antipsychotics } & Yes & $30(73.2)$ & $11(26.8)$ & \multirow[b]{2}{*}{0.538} & $28(93.3)$ & $2(6.7)$ & \multirow[b]{2}{*}{0.183} \\
\hline & No & 74(74) & $26(26)$ & & $71(84.5)$ & $13(15.5)$ & \\
\hline \multirow[t]{2}{*}{ Smoking } & Yes & $48(82.1)$ & $10(17.9)$ & \multirow[b]{2}{*}{0.109} & $8(88.9)$ & $1(11.1)$ & \multirow[b]{2}{*}{1.000} \\
\hline & No & $64(70.3)$ & $27(29.7)$ & & $92(87.6)$ & $13(12.4)$ & \\
\hline \multirow{2}{*}{ Serotonergic antidepressant } & Yes & $17(65.4)$ & $9(34.6)$ & \multirow[b]{2}{*}{0.320} & $11(68.8)$ & $5(31.3)$ & \multirow[b]{2}{*}{0.029} \\
\hline & No & $95(76.6)$ & $29(23.4)$ & & $94(90.4)$ & $10(9.6)$ & \\
\hline
\end{tabular}

* $\chi 2$ test, $\mathrm{t}$ test, or Mann-Whitney U test as appropriate; CGI=Clinical Global Impression; PRL=prolactin; Med.=median; SD=standard 
deviation; $\mathrm{IQR}=$ interquartile range.

${ }^{a}$ Risperidone-equivalent doses were calculated.

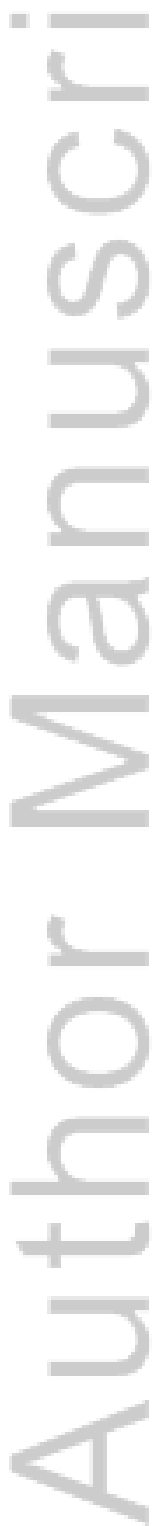


Table 3. Predictors of low bone mass determined in the multivariate analysis

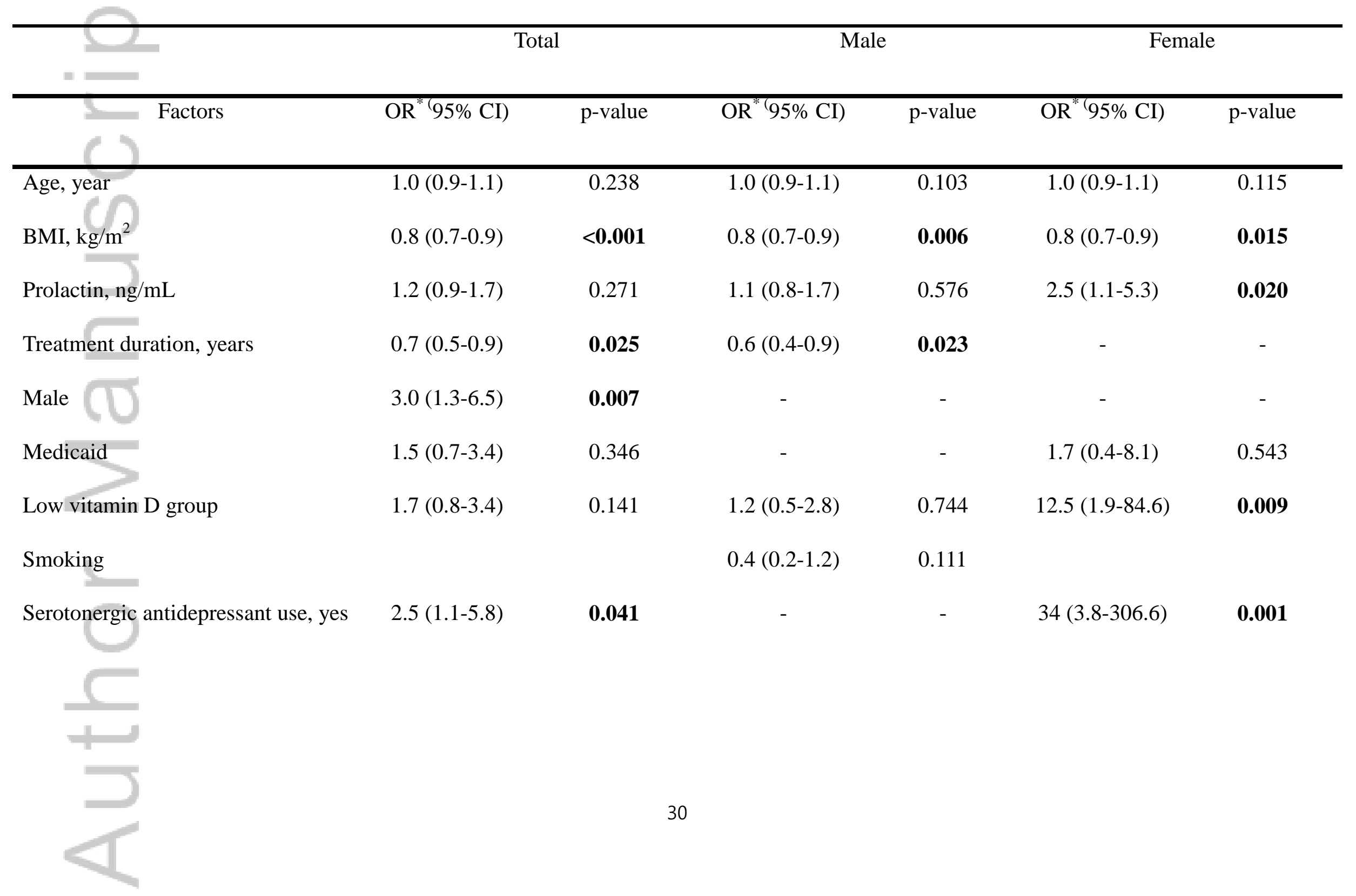

This article is protected by copyright. All rights reserved. 
* adjusted for all other variables in the model; $\mathrm{OR}=$ odds ratio, $\mathrm{CI}=$ confidence interval.

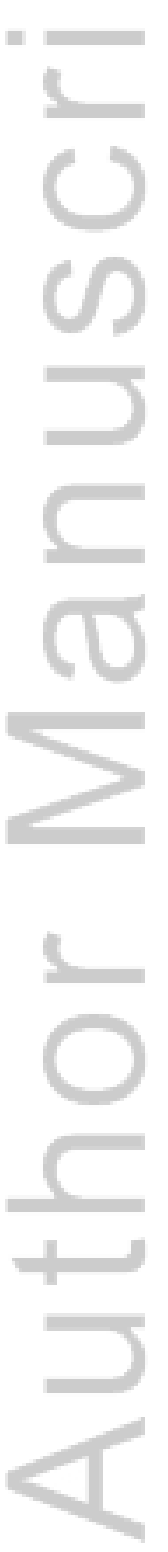

This article is protected by copyright. All rights reserved. 


\section{University Library}

\section{- M M N E R VA A gateway to Melbourne's research publications}

Minerva Access is the Institutional Repository of The University of Melbourne

Author/s:

Jhon, M;Yoo, T;Lee, J-Y;Kim, S-Y;Kim, J-M;Shin, I-S;Williams, L;Berk, M;Yoon, J-S;Kim, S-W

Title:

Gender-specific risk factors for low bone mineral density in patients taking antipsychotics for psychosis

Date:

2018-01-01

Citation:

Jhon, M., Yoo, T., Lee, J. -Y., Kim, S. -Y., Kim, J. -M., Shin, I. -S., Williams, L., Berk, M., Yoon, J. -S. \& Kim, S. -W. (2018). Gender-specific risk factors for low bone mineral density in patients taking antipsychotics for psychosis. HUMAN PSYCHOPHARMACOLOGY-CLINICAL AND EXPERIMENTAL, 33 (1), https://doi.org/10.1002/hup.2648.

Persistent Link:

http://hdl.handle.net/11343/283502 